\title{
Neurotoxicity in young adults 20 years after childhood exposure to lead: the Bunker Hill experience
}

Lynette Stokes, Richard Letz, Fredric Gerr, Margarette Kolczak, Fiona E McNeill, David R Chettle, Wendy E Kaye

\begin{abstract}
Objectives-An epidemiological study of young adults was conducted to determine whether environmental exposure to lead during childhood was associated with current adverse neurobehavioural effects.

Methods-The exposed group consisted of 281 young adults who had been exposed environmentally to lead as children and the unexposed referent group consisted of 287 age and sex frequency matched subjects. Information on demographics, past and current health, and past exposures to neurotoxicants, and responses to the
\end{abstract} Swedish Q16 questionnaire were collected by interview. Standard neurobehavioural and neurophysiological tests were administered by computer or trained technicians. $K \boldsymbol{x}$ ray fluorescence was used to estimate tibial bone lead concentrations among the exposed and unexposed groups. Associations were examined between the exposed group and referents and tibial bone lead concentration and the neurobehavioural and neurophysiological outcomes of interest.

Results-Among the measures of peripheral nerve function, after controlling for confounders, sural sensory nerve evoked response amplitude, peroneal motor nerve compound motor action potential amplitude, vibrotactile thresholds of fingers and toes, and standing steadiness were significantly associated with exposure group. Among the neurobehavioural tests, handeye coordination, simple reaction time latency, trails B latency, symbol digit latency, serial digit, and learning error score were also significantly associated with exposure group after controlling for confounders. Exposed subjects had significantly more neuropsychiatric symptoms than the referents. Associations between tibial bone lead concentration and scores for vocabulary, vibrotactile thresholds of the fingers, and vibrotactile thresholds of the toes approached significance.

Conclusions-Significant adverse central and peripheral neurological effects were found in a group of young adults 20 years after childhood environmental exposure to lead when compared with non-exposed controls. The absence of a significant association between neurological outcomes and tibial bone lead concentration, and the presence of significant associa- tions between neurological outcomes and exposure group may be due to either the magnitude of measurement uncertainty in $K \boldsymbol{x}$ ray films relative to the actual tibial bone lead concentration in these young non-occupationally exposed subjects, or uncontrolled confounding of the exposure group.

(Occup Environ Med 1998;55:507-516)

Keywords: neurological; neurophysiological; $x$ ray fluorescence; lead; epidemiology

The effects of inorganic lead on occupationally exposed adult populations have been well studied..$^{1-3}$ Less well studied and more controversial are the effects on adults of exposure to lead sustained during childhood. Some investigators have associated moderate exposure to lead in infancy and childhood with impairments of both the central nervous system (CNS) and peripheral nervous systems (PNS) in adults. ${ }^{4-11}$ However, other investigations have not consistently shown such effects. ${ }^{12-14}$ Previous studies of community exposures to lead have relied on surrogate measures of the total body burden of lead or cumulative lifetime dose. For example, blood lead concentrations obtained once or integrated over time have been used to estimate lifetime exposure to lead. ${ }^{15} 16$

$\mathrm{K} x$ ray fluorescence (KXRF) measurements of tibia lead content have been shown to be a measure of cumulative exposure to lead ${ }^{15-20}$ and the technique has been applied in studies of both occupational and environmental exposure to lead. ${ }^{152122}$ The technique is a direct measure of a person's lead burden and may therefore clarify exposure-effect relations which have previously been studied and assessed by other methods. Although potentially powerful, this method of exposure assessment has not been widely applied in the study of long term neurobehavioural and neurological effects among adults possibly resulting from childhood environmental exposure to lead.

KXRF was applied in the current epidemiological study of a sample of a larger cohort of young adults who were exposed to lead during childhood while living near a lead smelter in the Silver Valley, Idaho, USA. The objectives of the study were to determine whether childhood exposure to lead was associated with neurobehavioural, reproductive, and kidney function among adults. This report focuses on neurobehavioural and neurophysiological test results and on neurological symptoms.
This article is coved by copyright of the United States Government. 
Methods

SUBJECTS

The cohort consisted of 917 young adults 19-29 years of age who were from 9 months to 9 years of age during the period 1 January 1974 to 31 December 1975 and resided in one of five towns surrounding the lead smelter in the Silver Valley. The 1974-5 period was chosen because the smelter was known to have been operating without appropriate emission reducing devices during this period. Monthly lead emissions from the smelter averaged 8.3 metric tonnes in the years 1955-64, 11.7 metric tonnes from 1965 to September 1973, and 35.3 metric tonnes from October 1973 to September $1974 .^{8}$ Also, data from past blood lead surveillance of this population showed that mean blood lead concentrations among children 9 months to 9 years of age were $50.0 \mu \mathrm{g} / \mathrm{dl}$ in 1974 and $39.6 \mu \mathrm{g} / \mathrm{dl}$ in 1975 . Cohort members 9 months to 4 years of age were located from birth records and those 5-9 years of age from school records.

Birth and school records identified 2145 children who met these criteria. Of these, 43 were determined to be ineligible because the subject either had died or had not lived in one of the five towns; therefore, the final cohort comprised 2102 subjects. During initial locating efforts, 636 cohort members could not be located. From locating efforts that included Equifax credit bureau searches of cohort members or their parents, a review of current telephone directories from the Silver Valley, and a review of 1974 and 1975 telephone directories, 1466 subjects were successfully traced to their current address or telephone number. In July 1994, 325 cohort members could not be located, 92 could not be reached during the study period, 39 were identified as ineligible when contacted, and 93 refused to participate. The overall response rate was $91 \%$ (917 of 1010).

To identify control subjects, records were used from the Washington Department of Licensing Records. The names of 42232 male and female licensed drivers between the ages of 19 and 29 who resided in Spokane, Washington, were received on computer disk in June 1994. A random sample of 6993 records of licensed drivers was obtained, from which current telephone numbers and addresses were located for 2489 subjects. Of the 2489 subjects for whom addresses and telephone numbers were available, 1267 were ineligible because they no longer lived at the address, were unavailable for interview, or had previously lived in the Silver Valley; 468 refused to participate, and 754 completed telephone interviews. The overall response rate from control subjects was $62 \%(754 / 1222)$.

To obtain a subsample of the larger cohort for invitation to participate in medical testing, a random sample was drawn from exposed and referent subjects who completed telephone interviews. A total of 563 of the 917 interviewed exposed subjects were asked to participate in medical, neurobehavioural, and laboratory testing, and of these, $281(50 \%)$ agreed to participate. A total of 463 of 754 interviewed referent subjects were asked to participate in the study and $287(62 \%)$ agreed to participate. The results presented here were obtained during the medical testing phase of the study.

\section{DATA COLLECTION}

Telephone interviews were conducted with the 917 cohort members between 10 July and 7 August 1994. Information was collected about medical, reproductive, occupational, and residential histories. Socioeconomic and demographic characteristics were included in the telephone interview. Also, a 16 item standardised questionnaire designed to assess chronic neuropsychiatric disturbances was administered. $^{23}$

Participation in medical testing consisted of completion of a battery of neurophysiological and neurobehavioural tests (see later) that was used to determine the functional status of both the CNS and PNS. Also, KXRF of tibial bone lead concentration (see exposure assessment) was performed on each subject. Both exposed and referent subjects were tested between 8 August and 15 September 1994, at Sacred Heart Medical Center in Spokane, Washington. All subjects who participated in the clinical portion of the study provided informed consent.

\section{EXCLUSIONS}

One cohort member was excluded from the analysis because his mental disability required proxy responses from a family member. People with chronic conditions were removed from the analysis depending on which neurological test was assessed. For example, in analyses of vibration sensitivity measurements, subjects with current nerve damage as a result of trauma or other injury to the hand, arm, shoulder, or spine were removed $(n=29)$, as were subjects reporting diabetes $(n=7)$ and carpal tunnel syndrome $(n=18)$. In analyses from the neurobehavioural evaluation system, subjects were removed from the analyses for conditions or medications that may affect either the PNS or CNS; table 1 shows these conditions and medications.

NEUROBEHAVIOURAL AND NEUROPHYSIOLOGICAL TESTS

Study participants underwent manual and computerised neurobehavioural testing, as well as electrophysiological testing. ${ }^{24-36}$ All tests were performed in private rooms by technicians blinded to the subjects' exposure status. The testing protocol had seven components (table 2): electrophysiological; sensory; standing steadiness; motor; cognitive; mood; and Swedish Q16.

Twenty neurobehavioural outcome variables were initially selected to be sensitive indicators of a wide range of CNS and PNS functions. A portion of the questionnaire included the Swedish Q16 that asked about neurological symptoms and was administered one month before neurobehavioural testing. ${ }^{37}$ 
Table 1 Subject exclusion criteria for analyses of peripheral and central nervous system outcomes

\begin{tabular}{|c|c|c|c|c|c|c|}
\hline \multirow[b]{2}{*}{ Reason } & \multirow[b]{2}{*}{ PNS } & \multirow[b]{2}{*}{ CNS } & \multicolumn{2}{|c|}{ Exposed } & \multicolumn{2}{|c|}{ Unexposed } \\
\hline & & & $n$ & $\%$ & $n$ & $\%$ \\
\hline \multicolumn{7}{|l|}{ Medications: } \\
\hline Antidepressant & & $\mathrm{x}$ & 4 & 1.4 & 2 & 0.7 \\
\hline Antipsychotic & & $\mathrm{x}$ & 0 & 0.0 & 1 & 0.4 \\
\hline Anxiolytic & & $\mathrm{x}$ & 1 & 0.4 & 0 & 0.0 \\
\hline Hypoglycaemic & $\mathrm{x}$ & $\mathrm{x}$ & 2 & 0.7 & 1 & 0.4 \\
\hline Opiate & & $\mathrm{x}$ & 1 & 0.4 & 1 & 0.4 \\
\hline Antiseizure & & $\mathrm{x}$ & 0 & 0.0 & 1 & 0.4 \\
\hline \multicolumn{7}{|l|}{ History of: } \\
\hline Cancer & $\mathrm{x}$ & & 1 & 0.4 & 3 & 1.1 \\
\hline Diabetes & $\mathrm{x}$ & & 2 & 0.7 & 1 & 0.4 \\
\hline Seizures & & $\mathrm{x}$ & 7 & 2.5 & 3 & 1.1 \\
\hline Renal dialysis (current) & $\mathrm{x}$ & $\mathrm{x}$ & 1 & 0.4 & 0 & 0.0 \\
\hline Mental retardation & & $\mathrm{x}$ & 1 & 0.4 & 0 & 0.0 \\
\hline Hereditary polyneuropathy & $\mathrm{x}$ & & 1 & 0.4 & 0 & 0.0 \\
\hline Multiple sclerosis & $\mathrm{x}$ & $\mathrm{x}$ & 1 & 0.4 & 0 & 0.0 \\
\hline Self reported heavy drinking & $\mathrm{x}$ & $\mathrm{x}$ & 7 & 2.5 & 3 & 1.1 \\
\hline \multicolumn{7}{|l|}{ Subjects excluded (total $n$ ) } \\
\hline PNS outcomes & & & 13 & 4.6 & 7 & 2.4 \\
\hline CNS outcomes & & & 24 & 8.5 & 11 & 3.8 \\
\hline \multicolumn{7}{|l|}{ Subjects not excluded (total n) } \\
\hline PNS outcomes & & & 268 & 95.4 & 280 & 97.6 \\
\hline CNS outcomes & & & 257 & 91.5 & 276 & 96.2 \\
\hline
\end{tabular}

EXPOSURE ASSESSMENT

KXRF was used to measure tibia lead concentration, expressed as $\mu \mathrm{g} \mathrm{Pb} / \mathrm{g}$ bone mineral, as an index of long term exposure. ${ }^{18}$ About $3 \mathrm{~cm}$ of the left tibia midshaft was measured. Before measurement the skin surface was cleaned with isopropyl alcohol to reduce contamination. Each measurement took 30 minutes and required an effective dose of $35 \mathrm{nSv} .{ }^{20}$ System performance, defined as twice the median individual uncertainty on in vivo results, was $9 \mu \mathrm{g}$ $\mathrm{Pb} / \mathrm{g}$ bone mineral. Two similar systems were used, one from the University of Maryland, ${ }^{17}$ the other from McMaster University. ${ }^{19}$ To ensure compatibility of data, the same set of calibration and quality assurance standards were used for both systems and both systems used the same analytical software to derive lead concentrations. When true bone lead concentrations are near zero and measurement uncertainty is large, the distribution of bone lead concentration includes negative values. These conditions are often present when KXRF measures of bone lead concentration are performed on non-occupationally exposed subjects, and consequently, negative values for bone lead concentrations are commonly found when this technique is used in such populations.

\section{STATISTICAL METHODS}

All statistical analyses were performed with the SAS statistical software package. ${ }^{38}$ Exposure was defined as ever or never having lived in one of the five towns surrounding the smelter during the period 1974-5. Also, tibial bone lead measurements were used as a cumulative exposure to lead index. After excluding from data analysis those subjects meeting earlier exclusion criteria-for example, diabetes or mental retardation-differences in mean test

Table 2 Tests of neurophysiological and neurobehavioural function administered to referents and young adults exposed to lead as children

\begin{tabular}{|c|c|c|c|}
\hline Test & Function/domain & $\begin{array}{l}\text { Direction of } \\
\text { performancet }\end{array}$ & Score \\
\hline Electrophysiological ${ }^{33}$ : & Sensory/motor & & \\
\hline Sural sensory NCV & & + & Velocity $(\mathrm{m} / \mathrm{s})$ \\
\hline Sural sensory amplitude & & + & $\mu \mathrm{v}$ \\
\hline Peroneal motor NCV & & + & Velocity $(\mathrm{m} / \mathrm{s})$ \\
\hline Peroneal motor amplitude & & + & $\mathrm{mv}$ \\
\hline Peroneal F wave (latency) & & + & $\mathrm{ms}$ \\
\hline Heart rate variability ${ }^{34}$ & Autonomic & - & CV of R-R intervals \\
\hline \multicolumn{4}{|l|}{ Sensory: } \\
\hline Contrast sensitivity ${ }^{35}$ & Vision/sensory & + & Correct (n) \\
\hline $\begin{array}{l}\text { Peripheral vibration } \\
\text { sensitivity }^{29-31}\end{array}$ & Sensory & & \\
\hline Dominant hand & & - & $\log _{10} \mu \mathrm{m}$ displacement \\
\hline Non-dominant hand & & - & $\log _{10} \mu \mathrm{m}$ displacement \\
\hline Dominant toe & & - & $\log _{10} \mu \mathrm{m}$ displacement \\
\hline Non-dominant toe & & - & $\log _{10} \mu \mathrm{m}$ displacement \\
\hline Standing steadiness ${ }^{32}$ : & Balance/vestibular & - & Sway speed $(\mathrm{cm} / \mathrm{s})$ \\
\hline \multicolumn{4}{|l|}{ Motor: } \\
\hline Dynamometer $^{28}$ & Strength/motor & + & Grip strength (kg) \\
\hline Grooved peg board $^{25}$ & Coordination/fine motor & & \\
\hline Dominant hand & & - & Seconds to completion \\
\hline Non-dominant hand & & - & Seconds to completion \\
\hline \multicolumn{4}{|l|}{ Santa Ana ${ }^{24}$} \\
\hline Dominant hand & Coordination/motor & + & Pegs/30 s (n) \\
\hline Hand-eye ${ }^{\star}$ & Coordination $/$ motor & - & Root mean square error \\
\hline Finger tapping ${ }^{\star}$ & Coordination $/$ motor & + & Taps/30 s (n) \\
\hline \multicolumn{4}{|l|}{ Cognitive: } \\
\hline Simple reaction time ${ }^{\star}$ & Attention & - & Mean latency (ms) \\
\hline \multicolumn{4}{|l|}{ Trail making test ${ }^{27}$} \\
\hline Form A & Cognitive tracking & - & Time to completion (s) \\
\hline Form B & Concept shifting & - & Time to completion (s) \\
\hline Symbol digit substitution ${ }^{\star}$ & Coding & - & Errors $(\mathrm{n})$ \\
\hline Serial digit learning ${ }^{\star}$ & Learning/attention & - & Errors (n) \\
\hline Raven's progressive matrices ${ }^{26}$ & Non-verbal intelligence & - & Errors (n) \\
\hline Vocabulary ${ }^{\star}$ & Verbal intelligence & + & Correct $(\mathrm{n})$ \\
\hline \multicolumn{4}{|l|}{ Mood: $\star^{\star}$} \\
\hline Tension & Tension $/ \mathrm{mood}$ & - & Symptom rated $(1-5)$ \\
\hline Depression & Depression $/ \operatorname{mood}$ & - & Symptom rated $(1-5)$ \\
\hline Anger & Anger/mood & - & Symptom rated $(1-5)$ \\
\hline Fatigue & Fatigue/mood & - & Symptom rated $(1-5)$ \\
\hline Confusion & Confusion $/ \operatorname{mood}$ & - & Symptom rated $(1-5)$ \\
\hline Swedish Q16 & Symptoms & - & Yes responses $(\mathrm{n})$ \\
\hline
\end{tabular}

${ }^{\star}$ Computer administered neurobehavioural evaluation system (NES2). ${ }^{36}$

$\dagger^{+}=$higher score indicates better performance; $-=$higher score indicates poorer performance. 
Table 3 Demographic and other characteristics for exposed and referent populations

\begin{tabular}{|c|c|c|c|c|c|c|}
\hline \multirow[b]{2}{*}{ Characteristic } & \multicolumn{3}{|c|}{ Exposed } & \multicolumn{3}{|c|}{ Referent } \\
\hline & $n$ & Mean & $S D$ & $n$ & Mean & $S D$ \\
\hline Age $(y)$ & 257 & 24.3 & 3.18 & 276 & 24.2 & 3.02 \\
\hline \multicolumn{7}{|l|}{ Sex $(\%)$} \\
\hline Male & 122 & 47.7 & & 137 & 49.6 & \\
\hline Female & 135 & 52.3 & & 139 & 50.4 & \\
\hline \multicolumn{7}{|l|}{ Age distribution (\%): } \\
\hline $19-21$ & 64 & 24.9 & & 62 & 22.5 & \\
\hline $22-24$ & 62 & 24.1 & & 85 & 30.8 & \\
\hline $25-27$ & 78 & 30.4 & & 71 & 25.7 & \\
\hline $28-30$ & 53 & 20.6 & & 58 & 21.0 & \\
\hline \multicolumn{7}{|l|}{ Race/ethnicity (\%): } \\
\hline White & 252 & 98.0 & & 260 & 94.2 & \\
\hline Aleut Eskimo or Native American & 3 & 1.2 & & 4 & 1.4 & \\
\hline Asian or Pacific Islander & 0 & 0.0 & & 2 & 0.7 & \\
\hline African American & 0 & 0.0 & & 3 & 1.1 & \\
\hline Other & 2 & 0.8 & & 7 & 2.5 & \\
\hline \multicolumn{7}{|l|}{ Income (per annum) (\%): } \\
\hline$<\$ 10000$ & 33 & 12.8 & & 22 & 8.0 & \\
\hline$\$ 10000-19999$ & 77 & 30.0 & & 59 & 21.4 & \\
\hline$\$ 20000-29999$ & 55 & 21.4 & & 57 & 20.7 & \\
\hline$\$ 30000-39999$ & 32 & 12.5 & & 48 & 17.4 & \\
\hline$\$ 40000-49999$ & 24 & 9.3 & & 29 & 10.5 & \\
\hline$>\$ 50000$ & 19 & 7.4 & & 38 & 13.8 & \\
\hline Refused to declare & 17 & 6.6 & & 23 & 8.3 & \\
\hline Years of education (\%) & 257 & 12.6 & 1.67 & 276 & 13.8 & 1.64 \\
\hline$<12$ & 33 & 12.8 & & 9 & 3.3 & \\
\hline 12 & 112 & 43.6 & & 66 & 23.9 & \\
\hline $13-16$ & 108 & 42.0 & & 190 & 68.8 & \\
\hline$>16$ & 4 & 1.6 & & 11 & 4.0 & \\
\hline Missing & 1 & 0.4 & & 0 & 0.0 & \\
\hline \multicolumn{7}{|l|}{ Height $(\mathrm{cm})$ : } \\
\hline Male & 121 & 178.1 & 6.21 & 137 & 179.1 & 5.76 \\
\hline Female & 135 & 164.1 & 7.40 & 139 & 165.7 & 6.14 \\
\hline \multicolumn{7}{|l|}{ Weight $(\mathrm{kg})$ : } \\
\hline Male & 121 & 83.8 & 18.84 & 137 & 83.8 & 16.66 \\
\hline Female & 135 & 72.4 & 20.54 & 139 & 71.5 & 19.64 \\
\hline \multicolumn{7}{|l|}{ BMI $(\mathrm{kg} / \mathrm{m})$ : } \\
\hline Male & 121 & 28.3 & 5.34 & 137 & 26.0 & 4.28 \\
\hline Female & 135 & 26.8 & 7.32 & 139 & 26.0 & 6.92 \\
\hline Current blood lead (mean $\mu \mathrm{g} / \mathrm{dl}$ ) & 257 & 2.9 & 3.25 & 273 & 1.6 & 1.36 \\
\hline Blood lead 1974-5 (mean $\mu \mathrm{g} / \mathrm{dl})$ & 43 & 49.3 & 22.38 & - & - & - \\
\hline \multicolumn{7}{|l|}{ Bone lead $(\mu \mathrm{g} / \mathrm{g})(\%)$ : } \\
\hline$<1$ & 76 & 31.5 & & 130 & 50.4 & \\
\hline $1-5$ & 58 & 24.4 & & 66 & 25.6 & \\
\hline $5-10$ & 53 & 22.3 & & 50 & 19.4 & \\
\hline$>10$ & 52 & 21.8 & & 12 & 4.7 & \\
\hline \multicolumn{7}{|l|}{ Cigarette smoking: } \\
\hline Current smokers (\%) & 72 & 28.0 & 8.15 & 54 & 19.6 & 7.19 \\
\hline Cigarettes/day & 72 & 12.5 & & 54 & 13.1 & \\
\hline \multicolumn{7}{|l|}{ Alcohol consumption: } \\
\hline Current drinkers (\%) & 177 & 68.9 & 3.93 & 196 & 71.0 & \\
\hline Drinks/week & 174 & 2.6 & & 195 & 3.0 & 4.65 \\
\hline
\end{tabular}

scores between exposed and unexposed groups were compared with simple $t$ tests. Crude analyses with the mean (SD) were conducted on all examiner administered manual, computer administered neuropsychological and electrophysiological tests.

Subsequently, backward elimination stepwise multiple linear regression models were fitted separately to each of the 20 neurobehavioural test score variables to control for potentially confounding effects of important covariates of the neurological and neurobehavioural outcomes in this population. The initial set of covariates for the PNS outcomes included age, sex, height, body mass index (BMI), and skin temperature. The set of potential covariates of CNS function were age, sex, education (highest year completed), visual acuity, and an index of self reported effort in performing the tests (coded 1 to 4 ). Vocabulary score was used as an outcome rather than as a covariate because exposure to lead had occurred during the period of cognitive (including vocabulary) development, and controlling for a variable also affected by exposure to lead would have artifactually attenuated the esti- mates of associations between childhood exposure to lead and performance on the other neuropsychological tests. Average annual income was considered as a potential covariate, but was not included in the set because reduced current income might result from the effects of childhood exposure to lead on neurobehavioural function; also, controlling for current income would result in overcontrolling and biased estimates of the effect of exposure to lead on the outcomes. Although reduced years of education might be an effect of childhood exposure to lead, ${ }^{39}$ education was included as a potential covariate, even though doing so risked overcontrolling. Exposure group was forced into all the backward elimination stepwise regression models. The potential covariates were eliminated until only variables related (at the $\mathrm{p}<0.10$ level) to the outcome variable remained in the model. In general, any covariate that accounted for at least $1 \%$ of the total variance was retained in the models.

Results of these analyses are presented in terms of the standardised regression coefficients of the variables remaining in the models. Additional backward elimination stepwise regression models were fitted with the bone lead concentrations found (first as a continuous variable, then as a four level stratified variable) instead of the dichotomised exposure group variable in the models.

Frequencies of positive reporting of neuropsychiatric symptoms of the Swedish Q16 questionnaire in each of the two exposure groups and their corresponding crude odds ratios (ORs) were calculated for the 16 individual items and a dichotomised composite score ( $>4$ symptoms $v \leqslant 4$ symptoms). Backward elimination stepwise logistic regression models were also fitted to these variables with age, sex, and education included as potential covariates.

\section{Results}

Table 1 shows the number of participants in each exposure group excluded from data analyses of PNS and CNS outcomes due to their meeting initial exclusion criteria. Significantly more participants were excluded from the exposed group $(8.5 \%)$ than from the referent group (3.8\%), mainly due to self reported history of seizures and excessive current alcohol intake.

Table 3 shows the sociodemographic characteristics of the exposed and referent groups. The groups were comparable in terms of the age, sex, and race distributions. Compared with the referent group, the exposed population was less well educated, had lower annual incomes, consumed slightly more tobacco, consumed slightly less alcohol (after exclusion of subjects from both groups who reported drinking $>5$ drinks a day), and were slightly shorter (about $1 \mathrm{~cm}$ ). Weight and BMI were similar for the two groups. The mean current blood lead concentration was slightly higher for the exposed group $(2.9 \mu \mathrm{g} / \mathrm{dl})$ than for the referent group $(1.6 \mu \mathrm{g} / \mathrm{dl})$, but both were quite low. Historical blood lead concentrations 
Table 4 Mean (SD) of concentrations of lead in bone* in exposed and referent groups by age

\begin{tabular}{|c|c|c|c|c|c|c|c|}
\hline \multirow[b]{2}{*}{ Age group } & \multicolumn{3}{|c|}{ Exposed } & \multicolumn{3}{|c|}{ Referent } & \multirow{2}{*}{$\begin{array}{l}t \text { Test } \\
p \text { Value }\end{array}$} \\
\hline & $n$ & Mean & $S D$ & $n$ & Mean & $S D$ & \\
\hline $19-21$ & 58 & 1.47 & 8.35 & 61 & 1.27 & 6.60 & 0.88 \\
\hline $22-24$ & 60 & 4.48 & 7.45 & 81 & -0.61 & 6.19 & $<0.001$ \\
\hline $25-27$ & 69 & 4.82 & 8.92 & 64 & 0.60 & 8.60 & 0.006 \\
\hline $28-30$ & 51 & 6.64 & 9.53 & 52 & 1.74 & 6.42 & 0.002 \\
\hline
\end{tabular}

^Bone lead concentrations are in $\mu \mathrm{g} \mathrm{Pb} / \mathrm{g}$ bone mineral.

available for 43 of the exposed subjects examined were high, averaging $49.3 \mu \mathrm{g} / \mathrm{dl}$. This information was available from data collected by the Idaho Department of Health and Welfare.

Mean tibia lead concentrations were $4.6 \mu \mathrm{g}$ $\mathrm{Pb} / \mathrm{g}$ bone mineral (range -28.9 to 37.0 ) in the exposed group and $0.6 \mu \mathrm{g} \mathrm{Pb} / \mathrm{g}$ bone mineral (range -46.4 to 17.4 ) in the referent group. In the exposed group, $31 \%$ of subjects had concentrations $<1 \mu \mathrm{g} \mathrm{Pb} / \mathrm{g}$ bone mineral and $22 \%$ had concentrations $>10 \mu \mathrm{g} \mathrm{Pb} / \mathrm{g}$ bone mineral. By contrast, $50 \%$ of the referent group had concentrations $<1 \mu \mathrm{g} \mathrm{Pb} / \mathrm{g}$ bone mineral and $5 \%$ had concentrations $>10 \mu \mathrm{g} \mathrm{Pb} / \mathrm{g}$ bone mineral. Bone lead correlated significantly with age in the exposed group, but not in the referent group. When the subjects were divided into age subgroups (table 4) bone lead was significantly higher in all exposed subgroups except for those aged 19-21 years. For all subjects taken together, there was a weak correlation between current bone lead concentration and current blood lead concentration $(r=0.24)$.
For those exposed subjects for whom blood lead data were available from 1974-5 $(n=46)$, there was a modest correlation between current bone lead concentration and past blood lead concentration $(r=0.39)$.

Table 5 shows the crude mean scores for the neurological and neurobehavioural outcomes. All the observed crude differences in exposure group were in the direction of poorer performance by the exposed group than the referent group.

Among the electrophysiological measures, the crude mean sural sensory amplitude and peroneal motor amplitudes were found to be slightly smaller among the exposed group than among the referents. The corresponding nerve conduction velocities were similar between the two groups. Among the behavioural tests of peripheral nerve function, the crude mean vibrotactile thresholds of the fingers and standing steadiness both with eyes open and eyes closed showed differences that were significant between the exposed and referent groups. The crude mean coefficient of variation of the electrocardiographic R-R interval, visual contrast sensitivity, and vibrotactile thresholds of the toes seemed to be similar between the referent and the exposed groups. Crude mean differences for 11 of 12 motor and cognitive function tests were significant. The largest crude effects of exposure group were found for the hand-eye coordination, trails $\mathrm{B}$, symbol digit, serial digit learning, Raven progressive matrices, and vocabulary tests. Only for mean grip strength

Table 5 Mean (SD) of neurological tests in exposed and referent groups

\begin{tabular}{|c|c|c|c|c|c|}
\hline \multirow[b]{2}{*}{ Neurological test } & \multicolumn{2}{|c|}{ Exposed } & \multicolumn{2}{|c|}{ Referent } & \multirow{2}{*}{$\begin{array}{l}t \text { Test } \\
p \text { Value }\end{array}$} \\
\hline & $n$ & Mean (SD) & $n$ & Mean $(S D)$ & \\
\hline \multicolumn{6}{|l|}{ Electrophysiological: } \\
\hline Sural sensory NCV & 263 & $47.8(5.31)$ & 271 & $47.7 \quad(5.87)$ & 0.83 \\
\hline Sural sensory amplitude & 263 & $16.8(8.56)$ & 271 & $18.3(10.0)$ & 0.07 \\
\hline Peroneal motor NCV & 265 & $49.9(4.19)$ & 273 & 49.9 (3.81) & 0.98 \\
\hline Peroneal motor amplitude & 266 & $5.8(2.54)$ & 276 & $6.2(2.53)$ & 0.03 \\
\hline CV of R-R (rest) & 267 & $5.9(3.03)$ & 277 & $6.0 \quad(3.21)$ & 0.07 \\
\hline \multicolumn{6}{|l|}{ Sensory: } \\
\hline Contrast sensitivity & 267 & $5.5(1.36)$ & 278 & $5.6(1.25)$ & 0.39 \\
\hline Vibration sensitivity: & & & & & \\
\hline Dominant hand & 267 & $1.4(0.64)$ & 278 & $1.3(0.42)$ & 0.007 \\
\hline Non-dominant hand & 268 & $1.3(0.41)$ & 278 & $1.2(0.38)$ & 0.003 \\
\hline Dominant foot & 267 & $2.9(1.14)$ & 277 & $2.7 \quad(0.96)$ & 0.18 \\
\hline Non-dominant foot & 266 & $2.9(1.33)$ & 278 & $2.7 \quad(1.02)$ & 0.07 \\
\hline \multicolumn{6}{|l|}{ Standing steadiness: } \\
\hline Eyes open & 255 & $1.3(0.28)$ & 276 & $1.2(0.24)$ & 0.003 \\
\hline Eyes closed & 255 & $1.9(0.59)$ & 276 & $1.8(0.51)$ & 0.03 \\
\hline \multicolumn{6}{|l|}{ Motor: } \\
\hline Dynamometer & 267 & $36.7(12.8)$ & 278 & $38.0 \quad(12.49)$ & 0.22 \\
\hline Grooved peg board & & & & & \\
\hline Dominant hand & 267 & $61.9(9.96)$ & 278 & $59.7 \quad(7.97)$ & 0.003 \\
\hline Non-dominant hand & 268 & $67.2(11.7)$ & 277 & $64.5 \quad(11.22$ & 0.005 \\
\hline Santa Ana (dominant hand) & 267 & $46.2(5.58)$ & 278 & $47.6 \quad(5.56)$ & 0.004 \\
\hline Hand-eye coordination & 266 & $1.8(0.38)$ & 280 & $1.6(0.35)$ & $<0.0001$ \\
\hline Finger tapping & 267 & $149.2(20.3)$ & 280 & $153.2(21.2)$ & 0.02 \\
\hline \multicolumn{6}{|l|}{ Cognitive: } \\
\hline Simple reaction time & 256 & $258.6(37.1)$ & 276 & $250.42(29.3)$ & 0.004 \\
\hline Trailmaking A & 257 & $25.6(7.97)$ & 274 & $24.0 \quad(7.10)$ & 0.01 \\
\hline Trailmaking B & 256 & $62.0(22.6)$ & 274 & $51.4(15.7)$ & $<0.0001$ \\
\hline Symbol digit & 256 & $1.8(0.32)$ & 276 & $1.7 \quad(0.31)$ & $<0.0001$ \\
\hline Serial digit learning & 256 & $3.4(3.45)$ & 276 & $2.3(2.34)$ & $<0.0001$ \\
\hline Raven progressive matrices & 257 & $10.6(4.68)$ & 274 & $8.5(4.40)$ & $<0.0001$ \\
\hline Vocabulary & 255 & $13.3(6.76)$ & 276 & $17.0 \quad(6.26)$ & $<0.0001$ \\
\hline \multicolumn{6}{|l|}{ Mood: } \\
\hline Tension & 252 & $2.8(0.78)$ & 275 & $2.5 \quad(0.77)$ & $<0.0001$ \\
\hline Depression & 252 & $2.0(0.78)$ & 275 & $1.8(0.65)$ & $<0.001$ \\
\hline Anger & 252 & $2.2(0.84)$ & 275 & $1.9(0.68)$ & $<0.0001$ \\
\hline Fatigue & 252 & $3.0(0.83)$ & 275 & $2.7 \quad(0.81)$ & $<0.001$ \\
\hline Confusion & 252 & $2.4(0.79)$ & 275 & $2.0 \quad(0.67)$ & $<0.0001$ \\
\hline Swedish questionnaire 16 & 252 & 4.7 & 275 & 2.3 & 0.0001 \\
\hline
\end{tabular}


dynamometry were crude group differences not significant. Large crude mean differences were also found for all five of the mood scores and the neuropsychiatric symptom summary score from the Swedish Q16.

To control for potential confounding, backward elimination stepwise multiple linear regression models were fitted to all outcome variables. Table 6 shows the standardised regression coefficients from these models. In the final backward elimination stepwise linear regression models, sural sensory amplitude and peroneal motor amplitude were significantly related to exposure group. Height, BMI, and skin temperature remained in the model as significant covariates for sural sensory amplitude; and age, BMI, and skin temperature remained in the model as significant covariates for peroneal motor amplitude. Vibration threshold of the fingers and toes was significantly related to exposure. No covariates were retained in the model for the finger measure, whereas sex and height were retained in the model for the toe measure. Standing steadiness with eyes open as well as with eyes closed was significantly associated with exposure group after controlling for height and BMI. Regardless of significance, the estimated effect of being in the exposed group was negative for 11 of the 12 PNS outcomes analysed. The total variance accounted for by the multiple regression models of PNS outcomes varied widely $\left(R^{2}=0.03-0.53\right)$.

For the motor and cognitive outcomes, and after controlling for the effects of relevant covariates, exposure group was significantly associated with poorer performance on the handeye coordination, simple reaction time, trails $\mathrm{B}$, symbol digit, serial digit learning, Raven progressive matrices, and vocabulary tests (table 6). Regardless of significance, the estimated effect of being in the exposed group was negative for all 12 of the motor and cognitive outcomes analysed. Education was a significant covariate for all cognitive outcomes, regardless of the significance of the effect of exposure group. Age, sex, and self report of effort in performing the tests, as well as interviewer (not shown), were significantly related to some of the motor and cognitive outcomes. Also, the score from the Swedish Q16 was significantly associated with exposure group after controlling for the effects of relevant covariates. The total variance accounted for by the multiple regression models of motor and cognitive outcomes ranged from 0.06 to 0.69 .

To investigate relations between tibial bone lead and neurological and neurobehavioural variables, additional backward elimination stepwise multiple regression models were fitted that were identical to those just described except that tibial bone lead concentration was forced into the models rather than exposure group. Tibial bone lead concentration was not significantly related to any of the outcomes analysed. However, a trend for three measures approached significance: finger vibrotactile threshold $(p=0.09)$, toe vibrotactile threshold $(\mathrm{p}=0.08)$, and vocabulary score $(\mathrm{p}=0.06)$. Similar results were found when an exposure variable representing stratified (four strata) tibial bone lead concentration was used in the models rather than tibial bone lead concentration as a continuous measure.

In crude analyses, 15 of the 16 neuropsychiatric symptoms from the Swedish Q16 were found significantly more often among exposed than referent subjects. Relative frequencies of positive responses for the 15 items ranged from a low of $15.2 \%$ for perspire for no reason for

Table 6 Standardised regression coefficients from stepwise regression models for neurological and neurobehavioral outcomes

\begin{tabular}{|c|c|c|c|c|c|c|c|c|c|}
\hline Dependent variable & $\begin{array}{l}\text { Exposure } \\
\text { groupt }\end{array}$ & Age & Sex & Height & $B M I$ & Skin temperature & Education & Try hard & Model $R^{2}$ \\
\hline \multicolumn{10}{|l|}{ Electrophysiological: } \\
\hline Sural sensory NCV & 0.002 & - & - & -0.249 & 0.168 & - & - & - & 0.092 \\
\hline Sural sensory amplitude & $-0.102^{\star \star}$ & - & - & -0.255 & -0.125 & -0.256 & - & - & 0.179 \\
\hline Peroneal motor NCV & -0.026 & - & - & -0.404 & - & 0.284 & - & - & 0.207 \\
\hline Peroneal motor amplitude & $-0.100^{\star}$ & -0.089 & - & - & 0.131 & -0.184 & - & - & 0.054 \\
\hline Peroneal $\mathrm{F}$ wave latency $\ddagger$ & -0.009 & -0.057 & - & -0.734 & - & 0.077 & - & - & 0.534 \\
\hline $\mathrm{CV}$ of $\mathrm{R}-\mathrm{R}$ intervals & -0.022 & -0.112 & - & -0.119 & - & - & - & - & 0.027 \\
\hline \multicolumn{10}{|l|}{ Sensory: } \\
\hline Visual contrast sensitivity (D) & -0.011 & - & - & 0.103 & - & - & - & - & 0.011 \\
\hline Vibration threshold, fingers $\ddagger$ & $-0.163^{\star \star \star \star \star}$ & - & - & - & - & - & - & - & 0.027 \\
\hline Vibration threshold, toes $\ddagger$ & $-0.098^{\star \star}$ & - & -0.23 & -0.427 & - & - & - & - & 0.096 \\
\hline \multicolumn{10}{|l|}{ Standing steadiness: } \\
\hline Eyes open $\ddagger$ & $-0.120^{\star \star}$ & - & - & -0.150 & -0.120 & - & - & - & 0.050 \\
\hline Eyes closed $\ddagger$ & $-0.100^{\star \star}$ & - & - & -0.272 & -0.174 & - & - & - & 0.111 \\
\hline \multicolumn{10}{|l|}{ Motor: } \\
\hline Dynamometer & -0.32 & 0.076 & -0.614 & - & - & - & 0.160 & - & 0.689 \\
\hline Grooved pegboard $\ddagger$ & -0.071 & - & 0.283 & - & - & - & 0.215 & - & 0.113 \\
\hline Santa Ana pegboard & -0.026 & 0.076 & -0.093 & - & - & - & 0.131 & - & 0.073 \\
\hline Hand-eye coordination $\neq$ & $-0.193^{\star \star \star \star \star}$ & - & -0.332 & - & - & - & 0.140 & 0.085 & 0.197 \\
\hline Finger tapping & -0.046 & - & -0.327 & - & - & - & 0.100 & - & 0.131 \\
\hline Cognitive: & & & & & & & & - & \\
\hline Simple reaction time $\ddagger$ & $-0.090^{\star}$ & - & -0.223 & - & - & - & 0.216 & & 0.076 \\
\hline Trails A latency $\ddagger$ & -0.036 & - & 0.172 & - & - & - & 0.297 & - & 0.079 \\
\hline Trails B latency $\ddagger$ & $-0.169^{\star \star \star \star \star}$ & - & 0.183 & - & - & - & 0.373 & 0.090 & 0.183 \\
\hline Symbol digit latency $\ddagger$ & $-0.117^{\star \star}$ & -0.199 & 0.288 & - & - & - & & 0.088 & 0.277 \\
\hline Serial digit learning error $\ddagger$ & $-0.155^{\star \star \star}$ & - & - & - & - & - & 0.154 & - & 0.063 \\
\hline Raven errors $\ddagger$ & $-0.115^{\star \star}$ & - & - & - & - & - & 0.282 & 0.118 & 0.133 \\
\hline Vocabulary score & $-0.167^{\star \star \star \star \star}$ & 0.109 & - & - & - & - & 0.337 & 0.077 & 0.214 \\
\hline \multicolumn{10}{|l|}{ Swedish Q16: } \\
\hline Score $\ddagger$ & $-0.238^{\star \star \star \star}$ & - & -0.106 & - & - & - & 0.327 & - & 0.230 \\
\hline
\end{tabular}

${ }^{\star} \mathrm{p}<0.05 ;{ }^{\star \star} \mathrm{p}<0.01 ;{ }^{\star \star \star} \mathrm{p}<0.001 ;{ }^{\star \star \star \star} \mathrm{p}<0.0001$

†Exposure group was coded as $0=$ unexposed, $1=$ exposed

$\ddagger$ Scores inverted so that higher score indicates better performance. 
the exposed group $v 3.3 \%$ for the referent group to a high of $48.1 \% \vee 31.6 \%$ for have headache at least once a week. Crude ORs ranged from 1.79 for less interested in sex than normal to 5.33 for perspiring for no reason. Only the symptom difficulty buttoning or unbuttoning clothes, which is a negative control item in the Swedish Q16, did not show a significant difference between exposed $(2.0 \%)$ and referent $(1.1 \%)$ groups (crude $\mathrm{OR}=1.81,95 \%$ CI 0.43 to 7.66 ). Backward elimination logistic regression analyses containing variables for age, sex, and education as potential covariates yielded similar results. All of the items except two had parameter estimates that were significantly different from zero. Those two items were have headache at least once a week and the control item difficulty buttoning or unbuttoning clothes. Additional backward elimination stepwise logistic regression analyses did not show significant relations between tibial bone lead concentration and any of the neuropsychiatric symptoms.

\section{Discussion}

Results of central and peripheral neurological measures among a group of adults aged 19-29 years who were exposed environmentally to lead between ages 9 months and 9 years were compared with a similar group which was not known to be exposed to lead. Participants were classified as exposed and unexposed by location of residence, and tibial bone lead was measured by KXRF fluorescence to provide a biological assessment of current bone lead concentrations.

Among the tests of peripheral neurological function, while adjusting for potential confounders, evoked response amplitudes of the sural sensory and peroneal motor nerves, as well as vibrotactile threshold and postural stability measures, were significantly associated with exposure group. Among the CNS outcomes, after adjusting for potential confounders, significant associations were found between exposure group and hand-eye coordination, simple reaction time, trails $\mathrm{B}$, symbol digit, serial digit learning, Raven progressive matrices, and vocabulary tests, as well as the Swedish Q16 score. For all CNS outcomes and nearly all of the PNS outcomes, the estimated effect of exposure group was in the direction of poorer performance among the exposed than the referent group, even for those differences that did not achieve significance.

SOURCES OF BIAS

Several potential biases should be considered when interpreting the results of the present study. These include confounding bias, information bias in the form of error in estimation of exposure (reporting bias and measurement error), and error in identification of health outcome (observer and reporting bias, measurement error) and selection bias (poor response rates).

Firstly, it is possible that the associations found when exposure was dichotomised were, in fact, due to uncontrolled confounding by variables associated with group status. Efforts were made to measure the most important covariates of the outcomes used-for example, age and height for PNS outcomes, and sex and education for CNS outcomes - and to account for them with multivariate linear statistical models. It is possible that other variables, unmeasured in the current study, were not controlled and produced confounding bias that was unrecognised. For example, the referent group was identified from another community and may have differed for variables that have the potential to influence the outcomes usedfor example, parental IQ and quality of public education systems. However, these potential confounders were not measured, and historical data for them were not available.

Controlling the effects of neurological and neurobehavioural covariates that are likely themselves to be affected by exposure to lead - such as education - was particularly difficult. On a population basis, many of the neurobehavioural outcomes included in this study are, in part, a function of education. In turn, educational attainment has been shown to be dependent, in part, upon exposure to lead. ${ }^{39}$ Inclusion of educational attainment as an independent variable in models in which a measure of exposure to lead is also an independent variable would result in overcontrolling the association between lead and the outcome, and therefore attenuate the observed association. Despite this potential null bias, education was included in the statistical models of neurobehavioural outcome.

Because participants were not blinded to their exposure group, reporting bias may have occurred for some measures, especially those requiring subjective responses (such as the Swedish Q16) and those requiring a high level of effort and motivation by the participant, such as the neurobehavioural tests. However, several of the outcomes that were significantly associated with exposure group-for example, peroneal and sural nerve evoked response amplitudes-were completely objective and were, therefore, not subject to such reporting bias. These findings suggest that reporting bias is, at least, not fully responsible for the observed associations of neurological and neurobehavioural outcomes with exposure group.

It is unlikely that the neurophysiological and neurobehavioural test outcomes were influenced by observer bias. The technicians administering these tests were unaware of either each participant's exposure group or the results of tibial bone lead concentrations. Many of the tests were computerised and, therefore, consistent in their administration, making observer bias even less likely.

Several important biases in the null effect direction were likely to have occurred in the present study. In particular, heterogeneity of actual exposure within each of the exposure group categories, and errors in measurement of both tibial bone lead concentration and neurological or neurobehavioural outcomes were likely to have attenuated the observed associations between exposure and outcome. Specifically, exposure-effect relations between exposure group and neurological outcome 
would have been attenuated if relatively unexposed people were included in the exposed group and relatively exposed people were included in the referent group. Review of occupational and vocational histories did not show any known sources of exposure to lead among participants in either group other than the one actually used to define the exposure group (residence in the communities near the smelter). Also, current blood lead concentrations were low in both groups, suggesting no substantial current exposure to lead. However, the considerable overlap of the distributions of tibial bone lead concentrations among the two exposure groups suggests that, to some extent, exposure may have been misclassified despite the occupational histories and current blood lead concentrations.

Error in KXRF measures was substantial in this study, although not dissimilar to error found in other studies of similar, nonoccupationally exposed groups. In the current study, the mean uncertainty of the KXRF measures (a standardised estimate of measurement precision) was $4.8 \mu \mathrm{g} / \mathrm{g}$ across all participants (mean tibial bone lead=2.7 $\mu \mathrm{g} / \mathrm{g}$ ). By comparison, Kim et $a l^{40}$ obtained a mean uncertainty of $5.0 \mu \mathrm{g} / \mathrm{g}$ in a population with a mean tibial bone lead of $1.3 \mu \mathrm{g} / \mathrm{g}$ and Hoppin et $\mathrm{al}^{41}$ obtained a mean uncertainty of $3.9 \mu \mathrm{g} / \mathrm{g}$ in a population with a tibial bone lead of $4 \mu \mathrm{g} / \mathrm{g}$. The relatively modest precision of this exposure estimate likely resulted in attenuation of observed associations between exposure and the neurological and neurobehavioural outcomes.

Error in measurement of neurobehavioural outcomes can be substantial, which limits the practical sensitivity of these measures in detecting the effects of exposures in epidemiological studies. However, this type of error can be overcome to some extent by increasing sample size. The sample size in the present study was large for this type of study. The precision in measurement of neurobehavioural outcomes in the present study was sufficient to find expected relations to known covariates that accounted for as little as $1 \%$ of the total variance. Also, the magnitude of the residual error in the regression analyses, which varied substantially among outcome measures, was similar to that found in other studies of neurobehavioural function. ${ }^{42}$

It is possible that the sample of subjects who actually participated in the current study were not representative of the actual exposed population. The overall response rate for the first phase of the study (telephone interviews) was $91 \%$ for exposed and $62 \%$ for referents and for the second phase (KXRF and neurological and neurobehavioural testing) was $50 \%$ among the exposed group and $62 \%$ among the referents. It is possible that associations found in the current study were biased by differences between those who chose to participate in the study and those who did not. Also, selection bias may have been introduced because the referent population was drawn from driver's licence records and included only those people without neurological effects that might prevent them from obtaining a driver's licence. Reconstructing the referent population from birth and school records and subsequent tracing would not have been possible.

COMPARISON WITH OTHER STUDIES OF TIBIAL BONE LEAD MEASURED BY KXRF

The average tibia lead content of the exposed subjects in this study, $4.6 \mu \mathrm{g} \mathrm{Pb} / \mathrm{g}$ bone mineral, is much lower than concentrations found in studies of occupationally exposured subjects. ${ }^{15} 4344$ Tibia lead contents have been reported for several community based studies for several age groups. Average tibial concentrations have ranged from three to $21 \mu \mathrm{g} \mathrm{Pb} / \mathrm{g}$ bone mineral and some dependence with age has been found. ${ }^{45-50}$ The concentrations determined here for young adults are comparable with other studies of environmental exposure within this age group.

\section{COMPARISON WITH OTHER STUDIES OF} NEUROBEHAVIOURAL AND NEUROLOGICAL EFFECTS OF LEAD

The results of the present study are supported by previous studies of adults exposed to lead during childhood. ${ }^{39}{ }^{52}$ White et al followed up adults 50 years after childhood lead poisoning (hospital records showed symptoms consistent with blood lead concentrations of 60-100, $90-120$ and $>120 \mu \mathrm{g} / \mathrm{dl}$ ); results showed poorer performance on cognitive and motor function tests. $^{51}$ The neurological tests investigated in the present study did not allow direct comparison with the study of White et al because the mean age of that study population was 55 years and the exposure to lead was presumably acute lead poisoning, whereas the mean age of the present study population was 24 years and the exposure was to environmental lead from a lead smelter.

Needleman et $a l^{39}$ investigated a cohort 11 years after childhood exposure to lead (exposure to lead was determined from dentine concentrations of teeth shed at ages 6 and 7 years). Results showed deficits in cognitive and motor function tests. Furthermore, subjects were seven times more likely not to have graduated from high school if their previous dentine lead concentrations were $>20 \mathrm{ppm}$. It is noteworthy that in the present study, more exposed subjects than referents reported having less than a 12 th grade education, $14.2 \%$ v $3.1 \%$, respectively.

A smaller subset of the cohort of Needleman et al was investigated by Bellinger et $\mathrm{al}^{52}$ who recruited 79 subjects, aged 19 and 20 years, with dentine concentrations $>24 \mu \mathrm{g} / \mathrm{g}$ or $<8.7$ $\mu \mathrm{g} / \mathrm{g}$. Exposure to lead was also determined by KXRF of the tibia and showed an average concentration of $1.6 \mu \mathrm{g} / \mathrm{g}$ (range -9 to 19 ). Results showed that dentine lead concentrations were inversely related to scores on two of four attention performance tests. Tibial bone lead was inversely related to scores for both digit symbol and cancellation tests. The investigators concluded that tibial bone lead was not associated with neuropsychological test scores, although significant differences were observed on two tests. 
Numerous past investigations have examined the relation between occupational exposure to lead and nerve conduction velocity. Only a few studies have reported results of evoked response amplitude associated with exposure to lead. In past studies of occupationally exposed subjects, the nerve conduction results found have not been entirely consistent. However, associations have been found between exposure to lead and both conduction velocity and evoked response amplitude..$^{53-55}$ We are aware of no studies of young adults in which either conduction velocities or evoked response amplitudes were reported. In the present study, nerve conduction velocity was not associated with any measure of exposure, but evoked response amplitudes of the peroneal motor nerve and sural sensory nerve were associated with exposure group.

\section{ASSOCIATIONS BETWEEN DICHOTOMISED}

EXPOSURE GROUP AND KXRF

Nearly all health outcome measures associated more strongly with dichotomised exposure classification (exposed $v$ referent) than with the continuously distributed tibia lead concentration. Possible explanations for this finding include: (a) poor analytical methods; $(b)$ high relative measurement variation at low bone lead concentrations; (c) an inherently weak relation between current bone lead and the toxicologically meaningful dose at the time of exposure; and (d) possible uncontrolled confounding of exposure group status.

It is unlikely that measures of tibial bone lead concentration were performed poorly. State of the art equipment was used and values obtained were similar to those obtained by other investigators. Mean values for members of the exposed group were higher than those for members of the unexposed group, as expected. Other factors are more likely to explain the lack of association between tibial bone lead concentration and neurological and neurobehavioural outcomes, factors such as the variability in KXRF measurements. Recently published studies have shown that, among nonoccupationally exposed groups, substantial variability is found in KXRF tibial bone lead measurements. Bellinger et $a \bar{l}^{2}$ found substantially stronger associations with dentine lead than with tibial or patellar bone lead concentrations and concluded that the KXRF measures of bone lead were not sufficiently precise to serve as markers of childhood lead absorption. Hoppin $e t a F^{0}$ also found substantial variability and had similar concerns about KXRF precision among non-occupationally exposed people. In the light of these observations, it is likely that the uncertainty of the KXRF measurements resulted in considerable attenuation of the associations found between tibial bone lead concentration and the neurological and neurobehavioural outcomes tested.

Finally, regardless of the precision of measurement, tibial bone lead concentration in young adulthood may not be a strong indicator of the toxicologically important dose of lead actually delivered to the critical target neurological tissues in childhood. Bone is a dynamic tissue; remodelling and turnover of mineral content associated with growth may result in bone lead concentrations that are not strongly associated with the actual historical dose. ${ }^{56}$

\section{Conclusions}

The current study is the only large epidemiological study to date to examine associations between tibial bone lead concentration and neurological and neurobehavioural outcomes. It was hypothesised that tibial bone lead concentration might be a useful surrogate for biologically meaningful community exposure to lead in young adults who were exposed 20 years earlier. In the current study, significant associations were found between dichotomised exposure group and neurobehavioural outcomes, but not between tibial bone lead concentration and neurobehavioural outcomes. Although tibial bone lead measurements from occupationally exposed groups have been useful in determining lead body burden, they may not currently have the precision necessary to measure community based exposure to lead in young adults. An alternative explanation may be that the associations found between neurobehavioural outcomes and exposure, classified as never or ever, may have resulted from uncontrolled confounding of exposure group.

1 Seppalainen AM, Hernberg S, Vesanto R, et al. Early effects of occupational lead exposure: a prospective study. Neurotoxicology 1983;4:181-96.

2 Bordo BM, Filippini G, Massetto N, et al. Electrophysiological study of subjects occupationally exposed to lead and with low levels of lead poisoning. Scand $\mathcal{f}$ Work Environ Health 1982;8(suppl 1):142-53.

3 Baker EL, Feldman R, White RA, et al. Occupational lead neurotoxicity: a behavioral and electrophysiological evaluation: study design and year one results $B r \mathcal{F}$ Ind Med 1984;41:352-69.

4 Benetou-Marantidou A, Wakou S, Micheloyannis J. Neurobehavioural estimation of children with life-long increased lead exposure. Arch Environ Health 1988;43:392-6.

5 Bellinger D, Leviton A, Waternaux C, et al. Longitudinal Bellinger D, Leviton A, Waternaux $C$, et al. Longitudinal
analysis of prenatal and postnatal lead exposure in early analysis of prenatal and postnatal lead exposure in early

6 del la Burde B, Choate MS. Early asymptomatic lead exposure and development at school age. F Pediatr 1976;87:63842 .

7 Faust D, Brown J. Moderately elevated blood lead levels: effects on neuropsychologic functioning in children. Pediatrics 1987;80:623-9.

8 Landrigan PJ, Baker EL, Feldman RG, et al. Increased lead absorption with anemia and slowed nerve conduction in children near a lead smelter. F Pediatr 1976;89:904-10.

9 Needleman HL, Gunnoe C, Leviton A, et al. Deficits in psychological and classroom performance of children with elevated dentine lead levels. N Engl F Med 1979;300:68995.

10 Wigg NR, Vimpani GU, McMichael PJ. Port Pirie cohort study. F Epidemiol Community Health 1988;42:213-9.

11 Winneke G, Beginn U, Ewert T. Comparing the effects of perinatal and later childhood lead exposure on neuropsyperinatal and later childhood lead exposure on ne

12 Baloh RW, Sturm R, Green B, et al. Neuropsychological Baloh RW, Sturm R, Green B, et al. Neuropsychological effects of chronic asymptomatic increased lead abso

13 Lansdowne RG, Shepherd J, Clayton BE, et al. Blood lead levels, behavior and intelligence: a population study. Lancet 1974;8:538-41.

4 Ernhart CB, Morrow-Tlucak M, Marler MR. Low level lead exposure in the prenatal and early preschool periods: early preschool development. Neurotoxicol Teratol 1987;9:25970 .

15 Gerhardsson L, Attewell R, Chettle DR, et al. In vivo measurements of lead in bone in long-term exposed lead smelter workers. Arch Environ Health 1993;48:147-56.

16 Somervaille LJ, Chettle DR, Scott MC, et al. In vivo tibia lead measurements as an index of cumulative exposure in . 174-81.

17 Todd AC, McNeill FE, Fowler BA. In vivo x-ray fluorescence of lead in bone. Environ Res 1992;59:326-35.

18 Chettle DR, Scott MC, Somervaille LJ. Lead in bone: sampling and quantitation using K x-rays excited by $109 \mathrm{~cd}$. pling and quantitation using K x-rays
Environ Health Perspect 1991;91:49-55. 
19 Gordon CL, Chettle DR, Webber CE. An improved instrument for the in vivo detection of bone lead. $\mathrm{Br} \mathcal{F}$ Ind $\mathrm{Med}$ ment for the in vivo

20 Todd AC, McNeill FE, Palethorpe JE, et al. In vivo x-ray fluorescence of lead in bone $\mathrm{K}$ x-ray excitation with CD sources: radiation dosimetry studies. Environ Res 1992;57: $117-32$.

21 Erkkila J, Armstrong R, Riihimaki V, et al. In vivo measurements of lead in bone at four anatomical sites: long term occupational and consequent endogenous exposure. $\mathrm{Br} f$ Ind Med 1992;49:631-44.

22 Gamblin C, Gordon CL, Muir DCF, et al. In vivo measurements of bone lead content in residents of southern Ontario. Appl Radiat Isot 1994:45:1035-8.

23 Hogstedt C, Anderson K, Hane M. A questionnaire approach to the monitoring of early disturbances in central nervous functions. In: Aitio A, Rihimaki V, Vainio $\mathrm{H}$, eds. The biological monitoring of exposure to industrial chemicals. Washington: Hemisphere, 1984.

24 Jeyaratnam J, Boey KW, Ong CN, et al. Neuropsychological studies on lead workers in Singapore. Br f Ind Med studies on lead

25 Haaland KY, Cleeland CS, Carr D. Motor performance after unilateral hemisphere damage in patients with tumor Arch Neurol 1977;34:556-9.

26 Istoc-Bobis M, Gabor S. Psychological dysfunction in lead and mercury occupational exposure. Revue Roumaine des Sciences Sociales-Serie de Psychologie 1987;31:183-91.

27 Halstead WC. Brain and intelligence. Chicago: University of Chicago Press, 1947.

28 Pasternak G, Becker CE, Lash A, et al. Cross-sectional neurotoxicology study of lead exposed cohort. Clin Toxicol 1989;27:37-51.

29 Schwartz BS, Bolla KI, Stewart W, et al. Decrements in neurobehavioral performance associated with mixed exposure to organic and inorganic lead. Am $\mathcal{f}$ Epidemiol 1993; 137:1006-21.

30 Gerr FE, Letz R. Reliability of a widely used test of peripheral cutaneous vibration sensitivity and a comparison of eral cutaneous vibration sensitivity and a comparis

31 Stokes L, Stark A, Marshall E, et al. Neurotoxicity among pesticide applicators exposed to organophosphates. Occup

32 Bhattacharya A, Shukla R, Bornschein R, et al. Postural disequilibrium quantification in children with chronic lead exposure: a pilot study. Neurotoxicology 1988;9:327-40

33 Seppalainen AM. Neurophysiological approaches to the detection of early neurotoxicity in humans. Crit Rev Toxicol 1988;18:245-98.

34 Murata K, Araki S. Autonomic nervous dysfunction in workers exposed to lead, zinc, and copper in relation to peripheral nerve conduction: a study of R-R interval variability. Am F Ind Med 1991;20:663-71.

35 Pifer JW, Friedlander BR, Kintz RT, et al. Absence of toxic effects in silver reclamation workers. Scand $\mathcal{f}$ Work Environ Health 1989;15:210-21.

36 Letz R. The neurobehavioral evaluation system: an international effort. In: Johnson BL, ed. Advances in neurobehavioral toxicology: applications in environmental and occupational ioral toxicology: applications in environmental and

37 Hogstedt C, Hane M, Axelson O. Diagnosis and health care aspects of workers exposed to solvents. In: Zenz C, ed.
Developments in occupational medicine. Chicago, IL: Year Book Medical Publishers, 1980:249-58.

38 SAS Institute. SAS language and procedures: usage, version 6, 1st ed. Cary, NC: SAS Institute, 1989

39 Needleman HL, Schell A, Bellinger D, et al. The long-term effects of exposure to low doses of lead in childhood: an 11 year follow-up report. N Engl F Med 1990;322:83-8.

40 Kim R, Rotnitzky A, Bellinger D. Longitudinal relationship between dentin lead levels in childhood and bone lead levels in young adults. Arch Environ Health 1996;51:375-82.

41 Hoppin JA, Aro A, Hu H, et al. In vivo bone lead measurement in suburban teenagers. Pediatrics 1997;100: 365.

42 Letz R. Covariates of computerized neurobehavioral test performance in epidemiologic studies. Environ Res 1993; 61:124-32.

43 Bleecker ML, McNeill FE, Lindgren KN, et al. Relationship between bone lead and other indices of lead exposure in smelter workers. Toxicol Lett 1995; 77:241-8.

44 Watanabe H, Hu H, Rotnitzky A. Correlates of bone lead and blood lead levels in carpenters. Am F Ind Med 1994;26: 55-64

45 Kosnett MJ, Becker CE, Osterloh JD, et al. Factors influencing bone lead concentration in a suburban community assessed by non-invasive k-x-ray fluorescence. FAMA 1994;271:197-203.

46 Hernandez-Avila M, Gonzalez-Cossio T, Palazuelos E, et al. Dietary and environmental determinants of blood and bone lead levels in lactating postpartum women living in Mexico City. Environ Health Perspect 1996;104:1076-82.

$47 \mathrm{Hu} \mathrm{H}$, Hashimoto D, Besser M. Levels of lead in blood and bone of women giving birth in a Boston hospital. Arch Environ Health 1996;51:52-8.

$48 \mathrm{Hu} \mathrm{H}$, Aro A, Payton M, et al. The relationship of bone and blood lead to hypertension. $\mathcal{F} A M A$ 1996;275:1171-6.

$49 \mathrm{Hu} \mathrm{H}$, Payton M, Korrick S, et al. Determinants of bone lead and blood lead levels among community-exposed middle-aged to elderly men. Am f Epidemiol 1996;144:74959.

50 Hoppin JA, Aro A, Williams PL, et al. Validation of k-xrf bone lead measurements in young adults. Environ Health Perspect 1995;103:78-83.

51 White RF, Diamond R, Proctor S, et al. Residual cognitive deficits 50 years after lead poisoning during childhood. $\mathrm{Br}$ f Ind Med 1993;50:613-22.

52 Bellinger $\mathrm{D}, \mathrm{Hu} \mathrm{H}$, Titlebaum $\mathrm{L}$ et al Attentional correlates of dentin and bone lead levels in adolescents. Arch Environ Health 1994;49:98-105.

53 Baker EL, Feldman RG, White RA, et al. Occupational lead neurotoxicity: a behavioral and electrophysiological evaluation. Br F Ind Med 1984;41:352-61.

54 Buchthal F, Behse F. Electrophysiology and nerve biopsy in men exposed to lead. Br F Ind Med 1979;36:135-47.

55 Rosen I, Wildt K, Bullberg B, et al. Neurophysiological effects of lead exposure. Scand $\mathcal{F}$ Work Environ Health 1983; 9:431-41.

56 Aufderheide AC, Wittmers LE. Selected aspects of the spatial distribution of lead in bone. Neurotoxicology 1992;13: 809-20. 